\title{
Synerging of Root Traits and Agronomic Practices in Common Bean Production Improvement under Acidic Soil
}

\author{
Daba Etana*, Tolossa Ameyu \\ Ethiopian Institute of Agricultural Research, Jimma Agricultural Research Center, Jimma, Ethiopia \\ Email address: \\ dabaetana2018@gmail.com (D. Etana) \\ ${ }^{*}$ Corresponding author \\ To cite this article: \\ Daba Etana, Tolossa Ameyu. Synerging of Root Traits and Agronomic Practices in Common Bean Production Improvement Under Acidic \\ Soil. American Journal of Environmental and Resource Economics. Vol. 6, No. 3, 2021, pp. 77-85. doi: 10.11648/j.ajere.20210603.11
}

Received: July 24, 2021; Accepted: August 16, 2021; Published: August 23, 2021

\begin{abstract}
The most challenging in twenty first century is the cause and consequences of Climate change and variability. It is hastening frequently by over population more in developing countries. Thus, it is affected several sectors, while Agriculture is the most vulnerable for climate change. As a result both biotic and abiotic factors are bottle neck for food security and sustainability. From abiotic factor, soil acidity is the frequently observed at area where received intensive rainfall due to top soil and metallic elements washed out. Soil acidity is arsenic, and causes abortion of expected production, especially susceptible crops such as Common bean. To overcome this problem, agronomic practices such as lime application, soil conservation techniques and appropriate root traits were reported. Root system architectures traits such as higher basal root number between 12 to 16 , basal root whorl number of around 4, and shallow root angle of less than $15^{\circ}$ were reported suitable to withstand soil acidity. Agronomic practices alone reported as it is tedious and also difficult to get complete genotypes with full of desired acidity resistance root traits. Hence several reported explained that using the desired root traits for acidity resistance genotypes and important agronomic practices obtained more valuable results as form of integration. Therefore, using the appropriate root traits and agronomic practices support with each other to reduces the syndrome of soil acidity impacts.
\end{abstract}

Keywords: Acid Soil, Climate Change, Common Bean and Root Trait

\section{Introduction}

Common bean is one of the most important from legume crop and diversified over the world. It is used as a source of nutrition, income-generation, improve soil fertility [6]. In food security, it plays a substantial role for farmers due to its early maturity, nutrient compositions, wider in adaptation, higher tolerance of harsh conditions than other legume species and nitrogen fixer [20]. Thus farmer in different region called its name "Dafe" which mean 'early maturing' in Afan Oromo language in Ethiopia. Hence, the common bean holds great promises for fighting hunger, due to its early mature. This desirable trait has contributed in diversifying and production about two-fold in the last decade.

Common bean is the second most important pulse crop in terms of productivity and area of production in Ethiopia [62]. The production was $520.8 \mathrm{t}$ thousand and the area of production was $306,186.6$ ha in 2018 with an average productivity of $1.7 \mathrm{t}^{-h^{-1}}$ [17]. However, this is still below expected the actual productivity which is estimated to be more than $3 \mathrm{t} \mathrm{ha}^{-1}$ indicating that around $1.3 \mathrm{t}^{-h^{-1}}$ of the expected yield is a lost every year [70]. This yield gap may be the result of a less improved variety with desirable characters, soil management, biotic, and abiotic factors. From abiotic factors, the impact of soil acidity is most crucial in south west Ethiopia where the region experiences high rainfall [30].

Acid soils comprise up to $50 \%$ of the world's potentially arable land and thus, are significant limitation to crop production worldwide [30]. In Ethiopia, a recent study showed that about $43 \%$ of the Ethiopian arable land has been affected by soil acidity and has resulted in substantial production losses [21]. This may be due to different factors such as high rainfall, frequent use acidic fertilizers and intensive agricultural practices.

Acid soils are a major causes of $P$ fixation in soil, increase $\mathrm{Al}^{3+}$ ion and promote other cat ion elements deficiency in the phase of soil colloid which substituted by $\mathrm{H}^{+}, \mathrm{Fe}^{2+}$, and $\mathrm{Mn}^{2+}$. 
However, the deficiency of available $\mathrm{P}$ in the acidic soil was oftenly reported [30]. Soil acidity reduced the overall growth and performance of common bean which ultimately resulted in a yield loss of about $60 \%$ regardless of their genetic differences [61]. Therefore, to overcome this problem several techniques are under study includes lime application, tolerance variety development and integrate management.

Soil acidity could be managed through different techniques, such as improving the farmland, reducing frequent use of acidic fertilizers, reducing intensive cultivation and development of acid tolerant varieties [65, 73]. Several studies regarding the role of lime in improving in land affected by acidity have been reported [2, 13, 73]. Lime (Calcium carbonate) is a material or powdered form of stone compound made up of calcium and carbonate which dissociate in soil after reaction use to buffer acidity source to change in to neutral $\mathrm{pH}$ value. However, practicing all methods at small-scale farmers in developing countries may not be easy. Integrated management option may, hence be the best way and preferable approach.

Liming has several benefits including, buffering soil acidity problem and reducing the toxicity effects of acidity on beneficial microorganisms. Various experiments conducted in different parts of the world showed that lime application to the acid soils was effective and provided yield increment more than $50 \%$ [12]. It play great role in increasing the availability of plant nutrients such as $\mathrm{Ca}, \mathrm{P}$, $\mathrm{Mo}$, and $\mathrm{Mg}$ in the soil and reducing the solubility and leaching of heavy metals [22]. However, using lime alone has been causes several drawbacks such as high rate per unit area, carbonation and so on to the small-scale farmer, it is used as mechanism to reduce soil acidity effects in seldom parts of the country. Therefore, using lime alone to combat the impact of soil acidity is very limited to at accessible areas and potential farmers.

The synergism effect of root system and acidity amendments plays important role in alternatives and complementary approaches in tolerance of soil acidity. Hirpha et al reported that field screening of common bean genotypes has demonstrated the presence of genetic variability in tolerating soil acidity [30]. For instance, Common bean genotype named New BILFA 58 (NB 58) was identified as the most tolerant andRobal was sensitive genotypes to soil acidity [30]. In addition, variability and heritability among common bean genotypes in phosphorus use efficiency was also reported [4, 79].

Use of desired root traits could be feasible and easy to practice alone and combined with agronomic management options, especially for the small holder farmers. In such cases, root traits have got priority in plant characters to be considered while developing acidity tolerant variety [13]. Roots are multicellular organs characterized by features such as gravitropic response, endogenous branching, root hairs and a protective root cap [38]. A common beat root characters; shallow root angle, basal root whorl number, lateral root length, phosphorus solubilizing root exudates, mycorrhizal symbioses, and hypocotyls root number play a great role in acidity resistance $[31,49 ; 56,79]$. Therefore, the root system is a principal plant organ in developing acidity tolerance in addition to providing absorption of water and essential nutrients from the soil. Hence, selection of cultivars with desired root traits could be used as a strategy to increase the uptake of limited and sensitive nutrients such as phosphorus and enhance grain yield of common bean in acid soils through strong plasticity of the root system [54, 65]. However, studies looking for desired root traits in relation to nutrient uptake under acid conditions are very limited $[30,73$, 13]

This report was most important for guiding the exploration of such important characteristics of crops and identifying varieties with those characters. Therefore, it is of paramount importance to assess integrated approaches including use of local varieties with desirable root traits options to alleviate the problem of soil acidity and ultimately improve nutrient uptake for improved grain yield. Therefore this review was focused on importance of common bean root traits and agronomic managements used for reduce acidity syndromes

\section{Result and Discussion}

\subsection{Common Bean: It's Biology and Ecology}

Common bean (Phaseolus vulgaris L.) is a versatile diploid $(2 \mathrm{n}=2 \mathrm{x}=22)$ self-pollinated crop and the most widely grown pulse in more than four continents [27]. It is usually referred to as food legumes which belong to genus Phaseolus, species vulgaris, family Fabaceae, subfamily Papilionoideae, tribe Phaseoleae, sub-tribe Phaseolinae [59].

The center of origin is South America in andean region (mainly Peru) and Middle America around southern Mexico and high lands of Guatemala [18]. To confirm this, more than 50 genus Phaseolus wild-growing species distributed in America [63]. It is believed that introduced into Ethiopia in the $16^{\text {th }}$ century through Portuguese merchants [35].

Common bean is hermaphroditic, containing both the stamen and pistil in the same flower which is regarded primarily suitable for self-pollination [56]. It represents a wide range of life histories (annual to perennial), growth habits (bush to climbing), reproductive systems and adaptations from cool to warm and dry to wet ecologies [18]. It produces a dicotyledonous seed which is uses for source of nutrients and covers the embryo.

Common bean may have different in size, color, and even nutrients value based on their origin. The Andean lines have larger seeds in which 100 seed weight is above 30 grams while meso American lines are smaller seed size i.e., their 100 seed weight is less than 30 grams [64]. It exhibits different characters like bush type determinate and indeterminate, flat indeterminate and extreme climbing indeterminate types [50].

A Common bean is adapted to a wide range of climatic conditions ranging from 600 to $3000 \mathrm{~m}$ above sea level but depend on their genotypes [18]. However, it grows best in a warm climate at a temperature of 18 to $24^{\circ} \mathrm{C}$ ranges, and 
altitudes of 1400 to 2000 m.a.s.l. [71]. Kay, D.E. reported that the crop is well adapted to areas that receive an annual average rainfall ranging from $500-1500 \mathrm{~mm}$, and a frost-free period of 105 to 120 days for maturity [37]. The soil type which is suitable for optimum common bean production is deep, friable and well-aerated soil types with an optimum $\mathrm{pH}$ range of 6.0 to 6.8. The major common been producing areas of Ethiopia are central, eastern and southern parts of the country [14].

\subsection{Common Bean Production Status in Ethiopia}

The role of common bean in the society of the producers and consumers is well known especially at small-scale farmers. Thus majorities of common bean production participants in the country are small scale farmers. The amounts of different Ethiopian regions participated and contributed in the common bean production is quite different. For instance, Oromia region produces around 40\%, SNNPR (20\%), Amhara (29\%), Benshangul-Gumuz and Tigrary produced around $1.5 \%$ independently, and the others produced little in the lefted regions [14]. Furthermore due its desired characters like early maturing less competition in nutrients, intercrop common bean with production is more diversified and preferred by the farmers.

Common bean is widely adapted, maturing early, improves soil fertility and provides a source of nutrients [44]. Due to its importance of multipurpose, production area and yield increased year to year. It is the second in terms of area coverage and production with 311583.58 ha and $552564.07 \mathrm{t}$, respectively [14]. The average productivity of the common bean was $1.77 \mathrm{t} . \mathrm{ha}^{-1}$ which is far less than the attainable yield (2.5-3 t.ha $\left.{ }^{-1}\right)$ under good management conditions. This low yield is attributed to several production constraints, which include lack of improved seed, edaphic factors, poor agronomic practices, low integration, less advanced science, intensive cultivation, and inappropriate field operations [57].

\subsection{Common Bean in Soil Fertility Improvement}

Soil conservation activities have been the oldest and culturally practiced in the ancient period. The art of farmers to improve his/her cultivation field was incredible and extensive across farmers to farmers and place to place based on arts of experiences, environmental conditions, and even geographical topography. The uses of different species of legume crop are the most common and frequently practiced all over the world of agricultural field improvements.

The leguminous families of plants plays significant role in soil improvements; include wild and edible types. However, ratios and techniques of improvements are quietly different. It is considered as most common ways of biological soil conservation. In fact, without scientifically calculation, farmers easily habituate the significant differences of agricultural land treated with legume crop types. From the listed important legume crops in soil improvement, common is the commonly known and practiced and widely of agro ecologies. Hence, it has substantial role in improving soil fertility.

Legumes are using frequently as sources of nitrogen in improving soil fertility through the presence of nitrogenfixing bacteria in specialized organs (nodules) on the legume roots. There is fantastic report from global inorganic amounts of nitrogen demand, $60 \%\left(3 \times 10^{9} \mathrm{t} \mathrm{N}_{2}\right)$ is met by symbiotic nitrogen fixation, followed by chemical fertilizer (25\%) [81]. This shows that the importance or role of legumes in sustaining farming systems as world-wide. For instance, common bean added 57 to $100 \mathrm{kgha}^{-1}$ of nitrogen through fixing from the atmosphere through rhizobium bacteria $[17$, 29].

\subsection{Status and Distribution of Soil Acidity in the World and Ethiopia}

In high rainfall areas of Ethiopia, soil acidity is a problem and can lead to a decline or complete failure of crop production [1]. The extent of acidity is believed to increase from year to year due to major causes of anthropogenic (man-made) activities. Although soil acidity is a serious problem in the western and southwestern parts of Ethiopia, in-depth studies are scant on the causes and extent of acidity.

Soil acidity is a serious agricultural and environmental problem that limits the growth of crops and pastures in many parts of the world [19]. Ethiosis reported than more than $43 \%$ of Ethiopian farmland is affected by acidity [21]. This is highly revealed in the area where sloppy, intensive rainfall and utmost irrigated with excess acidifying fertilization [19]. For agricultural purposes, soils with $\mathrm{pH}$ values within the range of 5.5 to 6.5 are more suitable than those with higher or lower $\mathrm{pH}$ values

\subsection{Soil Acidity and Phosphorus (P) Constraints}

Soil acidity by itself has nothing or directly has no factor on growth and developments of plants. However, highly disturb natural flow system of macro and micro elements in the soil. Several elements may affect by different concentration level of acidity in the soil. However, the most sensitive element is Phosphorus. Acidity attack P availability in several directions. As acidity increase, solubility of Aluminum ( $\mathrm{Al}$ ) is increase because it is the most abundant elements in the soil. On the right hand, soil colloid is filling with Hydrogen ion and adsorption capacity of soil is reduced. On the left hand, $\mathrm{Al}^{+3}$ and $\mathrm{H}^{+}$compete with $\mathrm{P}$ absorption. Even though try to overcome the gap of nitrogen constraints through chemical $\mathrm{N}$ source application and atmospheric nitrogen fixation, major nutrients such as Phosphorus $(\mathrm{P})$ is become chronic problem in all over the world, specifically revealed frequently in Sub-Saharan African countries due to different reasons.

Most developing countries soils revealing low in $\mathrm{P}$ and depleting rapidly [25]. This is happening due to collect animals' product and crop residue from a field for fire wood. This causes boring agricultural commodity and less production. More, small scale farmer use low fertilizer rates since dominated major portion of developing countries such 
as Ethiopia. To secur food to the rapidly increasing population in developing countries, the need for $\mathrm{P}$ fertilizer and cost is expected to be increased [13]. The other challenge in $\mathrm{P}$ fertilizer is $70-90 \%$ fixed in the soil without contribution to the production [33].

Common bean with improved root traits were able to unlock and absorb P nutrient from the soil to tolerate acidity hindrances, and exudates hormone to increase soil volume via symbiotic relation with micro organism. The released organic compound creates mutualism within fauna and flora in the soil through root system and will expect to protect natural sustainability [61]. Through a better understanding of root nutrient acquisition under variable nutrient availability, it may be possible to selected a crop of better root traits to improve nutrient acquisition in specific environmental conditions and to increase agricultural productivity [15].

The other important characteristics for soil fertility improving is through symbiosis relation with rhizobium bacteria, mycorrhizal fungi, releasing organic acid into the soil and increasing root surface area [16]. The external hyphae permit the roots to tap large capacities of the soil, thereby absorbing $\mathrm{P}$ from non-labile sources and conveying it to the plant in exchange for organic elements released in soil by roots $[81,25,16]$. Through this relationship, roots absorb $\mathrm{P}$ which would otherwise be inaccessible to them from $\mathrm{P}$ deficient soils [69]. Therefore, the production of common bean has been a vital role in the cropping system by providing locked nutrients in the soil by unlocking, its cheapest and most effective approach to maintain sustainability in agriculture.

Soil acidity has a negative impact on seedling emergences, survival, establishment, root growth, nodulation and yield in common bean production [51]. The survival and the function of beneficial organisms such as rhizobia and mycorrhizae may also be inhibited by soil acidity. The detrimental effects of soil acidity normally occur when the soil $\mathrm{pH}$ falls below 4.8 measured in $\mathrm{CaCl}_{2}$ and are mainly due to toxicities of $\mathrm{Al}$, $\mathrm{Mn}$ and to some extent of $\mathrm{H}^{+}$ions [11]. In addition, deficiencies of essential nutrient elements such as $\mathrm{Ca}, \mathrm{Mg}, \mathrm{P}$, and Mo may also be involved [11].

In general, some influence of soil acidity on soil fertility and plant growth is a detrimental chemical condition of the soil reducing crop growth and yields. Greater quantities of $\mathrm{Al}$, $\mathrm{Fe}$, and $\mathrm{Mn}$ are toxic to almost all cultivated plants. The high concentration of these cations interferes with nutrient uptake, sugar phosphorylation and DNA synthesis [72]. In particular, nodule formation is sensitive to low soil $\mathrm{pH}$ and associated factors, e.g. Al and Mn toxicity, Ca deficiency and high soil temperatures [78].

\subsection{Soil Acidity Management}

\subsubsection{Acidity Buffering Materials}

Acidity is normally indicated by different levels of $\mathrm{H}^{+}$in a solution. Several materials are used to fix acidity problems in soils conditions. Liming is the cheapest and effective technique to buffer such a problem. However, liming has different advantages and disadvantages to the farmland [24].
Liming has several benefits including, its ability to reduce the toxicity effects of some microelements by lowering their concentrations while increasing the availability of plant nutrients such as $\mathrm{Ca}, \mathrm{P}, \mathrm{Mo}$, and $\mathrm{Mg}$ in the soil and reducing the solubility and leaching of heavy metals [22]. Crops absorb most of these nutrient elements particularly $\mathrm{Ca}, \mathrm{P}$, and $\mathrm{Mg}$ in substantial amounts and therefore by increasing their amounts in soil crop yields can be significantly improved. Various experiments studied in different parts of the world showed that lime application to the acid soil was effective and provided yield increment more than $50 \%$ [2, 12, 73]. In Ethiopia, the application of $2.7 \mathrm{tha}^{-1}$ lime and $30 \mathrm{~kg} \mathrm{ha}^{-1}$ of $\mathrm{P}$ was shown to result in higher grain yield as well as an economic advantage in common bean production [73].

Currently, liming is widely used in different acid affected soil in many countries including Ethiopia. The main drawback of liming is the high rate per unit area which demands higher costs for transportation and application. In addition, it may cause carbonation, sulfate attaches and environmental impacts [34]. Therefore, using lime alone to combat the impact of soil acidity is very limited to accessible areas and potential farmers. To improve such controversy, supporting with alternative and complementary approaches of controlling soil acidity having synergetic effects of each other could be an important solution.

\subsubsection{Common Bean Role in Soil Acidity Management}

Terrestrial flowering plants were developed from above and under-ground crucial organs. These organs adapted to the environment and responses to the influencing factors accordingly. The role of the root system in plant adaptation to nutrient limitation in the soil is not a singular issue [4]. The root is a fundamental component of plants [16] and it is a complex organ, and varieties of traits tedious to study. Plant root systems comprise a set of phenes (basic units of the phenotype) and root traits that interact with the environment, and are the identifiable units of the root phenotype [65].

Root architectural phenes are supported by root in morphology, anatomy, symbiotic, and biochemical products exudates from root surfaces. Spatially and temporally root architectural phenes are determined by root axes [47]. Every crop successive in acid soil is highly relied on phenotypic characteristics of the root, while adaptations to soils put in to give up stability and nutritional security in the face of nutrient deficiency through the total application of root system architectures accordingly.

Root system architecture (RSA) refers to in situ spatial distribution of the root system considering within the rooting volume, tap root, lateral roots and root hairs [25]. The root architectural traits include three general categories: topological properties (describing the pattern of root branching), geometric properties (the presence of roots in a spatial framework, such as the growth angle of root axes) and physiological properties such as root growth rate, root exudation and root water and nutrient use efficiency [16, 35, 42]. Root system architecture determines the crop capacity to acquire nutrients in the dynamic and variable soil 
environment [60].

Root systems are complex and a variety of root phenes have been identified as contributors to adaptation to soils with low fertility and aluminium (Al) toxicity. [48]. plants have evolved several strategies to deal with low soil $\mathrm{P}$ availability, including the exploration of a greater soil volume by changing root length and architecture; the differential allocation of root biomass in soil layers where there is a higher $\mathrm{P}$ concentration; the bio-stimulation and protocooperation with rhizosphere microorganisms that have $\mathrm{P}$ mobilization traits; the increase of $\mathrm{P}$ concentration in the soil solution through the root exudation of chemically active organic compounds into the rhizosphere; and an increase of $\mathrm{P}$ use efficiency by modifying their own physiology of tissue $\mathrm{P}$ allocation and use [80, 47]. More specifically, to increase the concentration of soil solution $\mathrm{P}$, some plants exude organic acid anions (OAs), such as citrate, oxalate, and malate, and also enzymes, such as phosphatases into the rhizosphere [36].

\subsection{Responses of Different Varieties of Common Bean to Acidic Soils}

Crop plants showed different responses to the stresses of edaphic and climatic factors. These characters support to withstand and resists current and future harsh environmental conditions. This noble characteristic of plants highly governed by genetic action the crop physiology. Hence, several crop plants reported their responses to soil acidity and $\mathrm{P}$ availability is limited. Regarding this problem of the crop in identification of genetic diversity, most genetic and physiological studies have focused on the major cereal crops such as wheat, rice and maize [30, 40]. Moreover, it is suggested that more attention should be paid to studies in crops which less attention given but high potential to resist acidity by their natural mechanism such as common bean [82].

In the tropics, several researchers have demonstrated genetic differences of common bean in tolerance to low-P conditions, i.e., the ability to produce economic yields with suboptimal $\mathrm{P}$ availability $[66,74,75]$. In at least one case, recommendations for $\mathrm{P}$ applications were tailored cultivar by cultivar, from 0 to $42 \mathrm{~kg} \mathrm{P} / \mathrm{ha}$, depending on the $\mathrm{P}$ requirements of the specific genotype. For instance, Thung, $\mathrm{M}$, reported that from several genotypes of common bean, Carioca is mostly grown in Brazil for such cases [75].

Similarly, few of African countries tried to investigate the varietal differences among the common bean genotypes including Ethiopia. Rwandaa climbing bean from Mexico, G2333, has gained great popularity among small farmers and is doubling yields over traditional bush cultivars in the central plateau [49]. They also demonstrate that low-P tolerance is not incompatible with high yield potential. In addition, Hirpha etal reported that varieties of common bean were available for $\mathrm{P}$ deficiency tolerant [30]. Several scientists proved out the most important traits to tolerate soil acidity in common bean is root traits and structures $[31,73$, 13]

\subsection{Root Traits of Common Bean Under Acidic Soils}

Every root trait has own role in scavenging soil nutrient in the soil. Soil with low phosphorus content is expressed higher degree $(>45)$ of root angle for searching available phosphorus in a soil. Superior root traits morphological (root length, root hairs) and physiological traits (root exudation of protons and phosphatase enzymes) that can enhance their dissolution and capture from the soils, can play a central role [25].

The following adaptation mechanisms to low-fertility soils or toxicity to soil acidity have been reported: release of phenolic compounds, mucilage formation and $\mathrm{pH}$ barrier resulting from increased $\mathrm{pH}$ in the rhizosphere [76] and organic acid exudation [26]. Roots of several plant species secrete organic acids in response to $\mathrm{Al}$, which are mediated by membrane transporters, resulting in the formation of non-toxic complexes with the metal. Thus, this mechanism prevents $\mathrm{Al}$ from crossing the plasma membrane into the symplast. Although organic acid exudation is a conserved Al tolerance mechanism being present in different plant species [41].

Root growth, development, and distribution across the soil profile are adversely affected by soil chemical constraints [28]. Improved adaptation of a crop to infertile soils can be achieved by two general approaches: the growth environment may be altered, or the plant genotype may be improved. Often a combined approach is the most effective. However, understanding the mechanisms by which plants adapt to infertile soils is critical for creating efficient strategies to develop stress-resistant cultivars for the sustainable intensification of production systems.

Defining specific mechanisms of adaptation to these soil constraints can contribute to the development of highthroughput phenotyping protocols improving the efficiency of the genetic improvement line up. Many common measures of the root system and individual root properties are examples of phene aggregates that are influenced by several, more elemental root phenes, and some are partially functional responses dependent on plant performance [80].

Generally, the long, dense root hairs, and the architectural phene of shallower basal root growth are synergetic for phosphorus acquisition [54]. The selection for root traits in common bean genotypes should preferentially be performed at the early pod-filling stage [4]. The other problems of soil acidity is syndrome of toxicity elements such as $\mathrm{Al}, \mathrm{Mn}$ and $\mathrm{H}$ ion toxicity limits root growth by restraining crops from reaching their yield potential [65]. This syndrome of soil acidity in crop production is steady grown from year to year due to natural and manmade causes. While to feed the current population of African continent which is more than 5 billion, soil fertility and healthiness problem is another headache in twenty first century. Therefore, improved varieties with appropriate mechanism to resist acidity syndrome will be the hope to sustain future production and productivity.

\subsection{Nutrient Availability and Its Impacts on Root Traits}

The fertility of the soil is non-static or not fixed characteristics of a soil. Root architectural plasticity might be 
an important factor in the acquisition by plants of immobile nutrients [3]. This means the fertility of the soil is either improved to rise or reduced when frequently used every year. While fertility of the soil is the issue of surviving of every individual organism in the food chain, the conservation strategy is still not really standardized, especially in developing countries. However, different methods of improving techniques are still ongoing.

The root system is directly contacted and interlinked with soil fertility and sustainable production of any crops. Indirectly the phsico-chemical characteristics of soil are expressed on the plant parts above ground through the growing period. The symptom revealed on the plant parts could be talk about the availability of the soil chemical existence in the soil. Every deficiency, optimum and excess level of soil essential element expressed directly related to above-ground plant parts and even roots characteristics.

The impact of soil nutrients availability on leguminous is the frequently raised and known on root structural surfaces. Mineral deficiencies other than $\mathrm{P}$ did not cause changes in the root angle [3]. Effects of $\mathrm{P}$ availability on root angle were associated with reduced shoot $\mathrm{P}$ concentration but preceded effects on plant biomass accumulation and leaf area expansion [43]. The relative immobility of $\mathrm{P}$ in soil renders the spatial configuration of a root system that was important for $\mathrm{P}$ acquisition. All root extension rate, lateral branching, and gravitropism are contribution of root architecture [3]. Root systems respond plastically to localized availability of nutrients such as $\mathrm{P}$ by proliferating roots in these patches [78].

\subsection{Phosphorus Deficiency in Common Bean Production}

In resource-poor farming, acidity induced nutrient deficiency is one of the constraints for the cultivation of common bean $[9,8]$. $\mathrm{P}$ is the most deficient nutrient in acid soils particularly when its concentration in the soil is less than $40 \mathrm{mg} \mathrm{P} \mathrm{kg}^{-1}$ soil [55]. Of the tropical soils, $43 \%$ are acid-weathered and if arranged in increasing order of weathering they are Andisols $<$ Ultisols $<$ Oxisols [54] and possess capacities to fix $\mathrm{P}$ in the range of 70 to $90 \%$ of $\mathrm{P}$ applied as inorganic fertilizers [68]. Because common bean requires $\mathrm{P}$ to enhance energy for its metabolic activities, the crop possesses high requirements for $\mathrm{P}$ and is, hence sensitive to low plant-available P in soils [10]. According to Kimani etal, P deficiency accounts for common bean yield loss of $253 \mathrm{~kg} \mathrm{ha}^{-1} \mathrm{yr}^{-1}$ in East Africa [39]. That crop loss is equivalent to a monetary loss of $\$ 303.6$. In order to address $\mathrm{P}$ deficiency for common bean and inability of smallholder farmers to afford P fertilizers, the International Center for Tropical Agriculture (CIAT) has spearheaded breeding programs in which several bean genotypes were screened for the ability to thrive in P-deficient soils [7, 46].

The common bean genotypes studied in acidity tolerant provided a yield of up to $1.4 \mathrm{t}$. ha ${ }^{-1}$, which better than the yield of 0.75 tha $^{-1}$ of the local common bean genotype grown on P-deficient soils [46]. Besides, the mechanism by which those new genotypes can thrive in P-deficient soils is not yet to be investigated. For example, whether the genotypes develop deep and massive root systems capable of exploring and extracting $\mathrm{P}$ and moisture from the deep soil layers needs to be explored.

Common bean has evolved several mechanisms for surviving under low levels of soil P. The main mechanisms are $\mathrm{P}$ acquisition efficiency and/or P utilization efficiency [5].

\subsubsection{Phosphorus Acquisition Efficiency Mechanisms}

Phosphorus acquisition efficiency can be achieved by the development of root architecture capable of foraging the nutrient [56]. In addition, it is the ability of a plant to mobilize and absorb more $\mathrm{P}$ from the fertile soil layers [5]. Phosphorus plays a vital role in increasing legume yield through its effect on the plant itself and also on the nitrogen fixation process by bacteria. For example, it is widely reported that phosphorus stress may led to reduced growth, and yield in field crops, including legumes, such as common bean [58]. Phosphorus stress reduces nitrogen fixation due to decreased nodule formation and reduced nodule sizes, and finally affecting the yield, and grain quality and quantity [61] Root hairs are effective in extending the width of the $P$ depletion zone around the root through increasing the volume of the soil explored for phosphorus. Root hairs substantially increased the root surface area for ion uptake. Some plant species/genotypes are adapted to produce longer and more root hairs under $\mathrm{P}$ deficient conditions [8, 9]. Miller reported that greater production of adventitious roots in common beans helps in $\mathrm{P}$ acquisition by improving plant foraging in the most $\mathrm{P}$ rich soil environment [56], while Beebe etal noted that basal root development has been responsible for efficient $\mathrm{P}$ acquisition [8]. In their separate studies, [9] observed that the shallower the basal root angle, and the greater total root length and root length of basal roots in the top $30 \mathrm{~cm}$ area, the greater the $\mathrm{P}$ uptake in the $\mathrm{P}$ limiting environment. Thus, the difference in these root traits elucidates the differences among common bean genotypes in $\mathrm{P}$ acquisition efficiency.

\subsubsection{Phosphorus Utilization Efficiency}

Phosphorus application improved rate of $\mathrm{P}$ supply to the soil or an improved ability of the plant to absorb $\mathrm{P}$, when $\mathrm{Al}$ toxicity has been eliminated, and enhanced the vegetative growth of common bean which resulted in increased dry biomass yield [45]. Large difference in biomass production among two different common bean varieties, in which Pefficient common bean varieties adapted better to the acidic soil conditions than the P-inefficient common bean varieties and showed greater biomass, especially under applied phosphorus.

\section{Conclusion}

Biotic and abiotic factors are commonly known plays role as positive or negative effects with each other to achieve their food chain and complex. The acts of an organism may cause either positive or negative on the other organisms. The physical appearance change on the phase of the earth happened of this result. However, the speed of biotic factor to 
change nature is faster than natural change. Fairly, soil acidity is believed to be existed as natural on the soil surface. However, the act of anthropology hurried its dissemination through agricultural and industrial by products. The major commonly known sources of soil acidity are intensive rainfall may cause leaching of metallic ion on the surface of soil colloids and use of acidic source fertilizers. Currently, around highland areas of countries like Ethiopia it may cause yield loss around $60 \%$. Thus it needs especial intervene to overcome such production hindrances. Lime application, and soil conservation practices the early action taken to reduce the impacts of acidic soil in production. Further use of acidic tolerant genotypes is more appropriate and sustainable solution for soil acidity problem. Finally, several traits may be indicated to reduce the impacts of acid soil. More use of appropriate crop varieties with desired traits such as root traits, and other genetic relation is recommended. To achieve sustainable acidity tolerant and reduce its impact, using the synergism of both agronomic practices and appropriate acidity tolerant crop genotypes may have play substantial role in to reduce acidic problems such as soil conservation and lime application give solution for the problems.

\section{References}

[1] Abdanna Deressa, Negassa Chewaka W. and Tilahun Geleto. (2007). Inventory of soil acidity status in croplands of Central and Western Ethiopia. Utilization of diversity in land use systems: Sustainable and organic approaches to meet human needs. Tropentag, 9-11.

[2] Alemu, F. and Alemu, T., (2015). Pseudomonas fluorescens Isolates used as a plant growth promoter of Faba Bean (Viciafaba) in vitro as well as in vivo study in Ethiopia. American Journal of Life Sciences, 3 (2), 100-108.

[3] Amy, B. Y. and Jonathan, M. B. (1996) 'Effect of phosphorus deficiency on growth angle of basal roots in Phaseolus vulgaris', 281-288.

[4] Araujo, A. P., Teixeira, M. G. and Almeida, D. L. D., 2000. Growth and yield of common bean cultivars at two soil phosphorus levels under biological nitrogen fixation. Pesquisa Agropecuária Brasileira, 35 (4), pp. 809-817.

[5] Atemkeng, M. F., Remans, R., Michiels, J., Tagne, A. and Ngonkeu, E. L. M. (2011). Inoculation with Rhizobium etli enhances organic acid exudation in common bean (Phaseolus vulgaris L.) subjected to phosphorus deficiency. African Journal of Agricultural Research, 6 (10), 2235-2242.

[6] Bareke, T., Asfaw, Z. and Woldu, Z. (2018). Diversity of common bean (Phaseolus vulgaris L., fabaceae) landraces in South Eastern Ethiopia. Advanced Plants Agricultural Resources, 8 (6), 449-457.

[7] Beebe, S., Rao, I., Blair, M. and Acosta, J. (2013). Phenotyping common beans for adaptation to drought. Frontiers in physiology, 4, 35-48.

[8] Beebe, Ramirez, J., Jarvis, A., Rao, M. I., Mosquera, G., Bueno, M. J., and Blair, W. M. (2011). Genetic Improvement of Common Beans and the Challenges of Climate Change. In S. S. Yadav, J. R. Redden, L. J. Hatfield, H. Lotze-
Campenand E. A. Hall (Edition.), Crop Adaptation to Climate Change 1, 356-369.

[9] Blair, M. W., Torres, M. M., Giraldo, M. C. and Pedraza, F., (2009). Development and diversity of Andean-derived, genebased microsatellites for common bean (Phaseolus vulgaris L.). BMC Plant Biology, 49 (1), 59-68.

[10] Boutraa, T. (2009). Growth and carbon partitioning of two genotypes of bean (Phaseolus vulgaris) grown with low phosphorus availability. Eurasian Journal of BioScience, 3 (3), 17-24.

[11] Buni, A., (2014). Effects of liming acidic soils on improving soil properties and yield of haricot bean. J. Environ. Anal. Toxicol, 5 (1), 1-4.

[12] Buri, M. M., Issaka, R. N. and Wakatsuki, T. (2005). Extent and management of low pH soils in Ghana. Soil Science and Plant Nutrition, 51 (5), 755-759.

[13] Burridge, J., Jochua, C. N., Bucksch, A., and Lynch, J. P. (2016). Legume shovelomics: high - throughput phenotyping of common bean (Phaseolus vulgaris L.) and cowpea (Vigna unguiculatasubsp, unguiculata) root architecture in the field. Field Crops Research, 192, 21-32.

[14] CSA (Central Statistical Agency). (2021). Agricultural sample survey 2020/21 report on area and production for major crops (private peasant holdings). Statistical bulletin Addis Ababa, Ethiopia.

[15] Champman D., (1965). Cation exchange capacity by ammonium saturation. In: black, C. A., L. E., Ensminger and F. E., Clark (Editions.). Method of soil analysis. American Society of Agronomy. Madison Wisconsin, USA. 891-901.

[16] Chen, Y. L., Djalovic, I. and Rengel, Z. (2015). Phenotyping for root traits. In Phenomics in Crop Plants: Trends, Options, and Limitations. 101-128.

[17] Cochrane, L. and Bekele, Y. W., 2018. Average crop yield (2001-2017) in Ethiopia: Trends at national, regional and zonal levels. Data in brief, 16, 1025.

[18] Demelash. (2018) 'Advances in Crop Science and Technology Common Bean Improvement Status ( Phaseolus vulgaris L.) in Ethiopia', Journal of Biotechnology, 6 (2). 1-18.

[19] Eberbach, P. and Black, A., (2003). Managing the Soil. In Principles of Field Crop Production. 233-272. Oxford University Press.

[20] Ephrem Terefe Lemu, (2016). Review of Haricot bean Value Chain in Ethiopia. International Journal of African and Asian Studies, 24, 2409 - 6938.

[21] Ethiosis., (Ethiopia soil information system (Ethiopia) (2014). Soil fertility mapping and fertilizer blending. Agricultural Transformation Agency (ATA) Report,. Ministry of Agriculture, Addis Ababa.

[22] Fageria, N. K., Baligar, V. C. and Li, Y. C. (2008). The role of nutrient efficient plants in improving crop yields in the twenty-first century. Journal of Plant Nutrition, 31 (6), 11211157.

[23] Fageria, V. C. Baligarand R. W. Zobel (2007) Yield, Nutrient Uptake, and Soil Chemical Properties as Influenced by Liming and Boron Application in Common Bean in a No-Tillage System, Communications in Soil Science and Plant Analysis, 38: $11-12$. 
[24] Fageria, N. K., and Baligar, V. C. (2005). Enhancing nitrogen use efficiency in crop plants. Advances in agronomy, 88, 97-185.

[25] Gahoonia, T. S. and Nielsen, N. E. (2004) 'Root traits as tools for creating phosphorus efficient crop varieties', 47-57.

[26] Garcia MJ, Romera F, Lucena C, Alc_antara E, Pe'rezVicente R. (2015). Ethylene and the regulation of physiological and morphological responsesto nutrient deficiencies. Plant Physiology 169: 51-60.

[27] Gepts, P., 1998. Origin and evolution of common bean: past events and recent trends. Hort Science, 33 (7), 1124-1130.

[28] Gregory P. (2006). Plant roots. Growth, activity, and interaction with soils. Oxford: Blackwell Publishing Ltd.

[29] Hardarson, G. (1993) 'Methods for enhancing symbiotic nitrogen fixation.', Plant and Soil, 152 (1), 1-17.

[30] HirphaLeggesse., Nigussie-Dechassa, R., Gebeyehu, S., Bultosa, G. and Mekbib, F. (2013). Response to soil acidity of common bean genotypes (Phaseolus vulgaris L.) under field conditions at Nedjo, western Ethiopia. Science, Technology and Arts Research Journal, 2 (3), 3-15.

[31] Ho, M. D., Rosas, J. C., Brown. K. M., Lynch. J. P., (2005). Root architectural tradeoffs for water and phosphorus acquisition. Function Plant Biology. 32. 737-748.

[32] Hodge, A., Berta, G., Doussan, C., Merchan, F. and Crespi, M. (2009). Plant root growth, architecture, and function. Plant and Soil, 321 (1-2), 153-187.

[33] Holford, I. C. R. (1997). Soil phosphorus: its measurement, and its uptake by plants. Soil Research, 35 (2), 227-240.

[34] Jawad, I. T., Taha, M. R., Majeed, Z. H. and Khan, T. A., (2014). Soil stabilization using lime: Advantages, disadvantages and proposing a potential alternative. Research Journal of Applied Sciences, Engineering, and Technology, 8 (4), 510-520.

[35] Judd, L. A., Jackson, B. E. and Fonteno, W. C. (2015) 'Advancements in Root Growth Measurement Technologies and Observation Capabilities for Container-Grown Plants', African Journal of Plant Science, 369-392.

[36] Jung, J. K. H. M. and McCouch, S. R. M. (2013). Getting to the roots of it: genetic and hormonal control of root architecture. Frontiers in plant science, 4, 186.

[37] Kay, D. E. (1979). Food Legumes. Tropical Product Institutes. 56/62 Gray's lnn Road London. 25.

[38] Kenrick, P. and Strullu-Derrien, C., (2014). The origin and early evolution of roots. Plant physiology, 166 (2), 570-580.

[39] Kimani, P., Buruchara, R. and Lubanga, L. (2006), Enhancing the Resilience of Agroecosystems in Central Africa through Improved, Nutrient Dense and Marketable Bean Germplasm Tolerant to Low Fertility Acid Soils. In the CIALCA Second Planning Workshop, Kigali 28, 1-34.

[40] Kochian LV, Piñeros MA, Hoekenga OA, (2005). The physiology, genetics and molecular biology of plant aluminum resistance and toxicity. Plant Soil, 274: 175-195.

[41] Kudoyarova, G. R., Dodd, I. C., Veselov, D. S., Rothwell, S. A. and Yu. Veselov, S. (2015). Common and specific responses to the availability of mineral nutrients and water. Journal of Experimental Botany, 66 (8), 2133-2144.
[42] Lamb, J. F. S., Johnson, L. D. and Barnes, D. K. (2000) 'A method to characterize root morphology traits in alfalfa'.

[43] Lambers, H., Cawthray, G. R., Giavalisco, P., Kuo, J., Laliberté, E., Pearse, S. J., Scheible, W. R., Stitt, M., Teste, F. and Turner, B. L. (2012). Proteaceae from severely phosphorus-impoverished soils extensively replace phospholipids with galactolipids and sulfolipids during leaf development to achieve a high photosynthetic phosphorususe-efficiency. New Phytologist, 196 (4), 1098-1108.

[44] Landon JR. 1991. Booker tropical soil manual: a handbook for soil survey and agricultural land evaluation in the tropics and sub-tropics. Longman Scientific and Technical, Longman Group, New York, USA,. 1-474.

[45] Liao, H., Rubio, G., Yan, X., Cao, A., Brown, K. M. and Lynch, J. P., (2001). Effect of phosphorus availability on basal root shallowness in common bean. Plant and Soil, 232 (1-2), 69-79.

[46] Lunze, L., Kimani, P. M., Ngatoluwa, R., Rabary, B., Rachier, G. O., Ugen, M. M. and Ruganza, V., (2007). Bean improvement for low soil fertility adaptation in Eastern and Central Africa. In Advances in Integrated Soil Fertility Management in Sub-Saharan Africa: Challenges and Opportunities, 325-332.

[47] Lynch JP. (2011). Root phenes for enhanced soil exploration and phosphorus acquisition: tools for future crops. Plant Physiology 156: 1041-1049.

[48] Lynch, J. P. and Brown, K. M., (2012). New roots for agriculture: exploiting the root phenome. Philosophical Transactions of the Royal Society B: Biological Sciences, 367 (1595), pp. 1598-1604.

[49] Lynch, J. P., and Brown, k.m., (2001). Top soil foraging- an architectural adaptation of plant to low phosphorus availability. Plant soil. 225-237.

[50] Margaret, N., Tenywa, J. S., Otabbong, E., Mubiru, D. N. and Ali, T., (2014). Development of Common Bean (Phaseolus Vulgaris L.) Production Under Low Soil Phosphorus and Drought in Sub-Saharan Africa: A. Journal of Sustainable Development, 7 (5).

[51] Marschner, P., Crowley, D. and Rengel, Z. (2011). Rhizosphere interactions between microorganisms and plants govern iron and phosphorus acquisition along the root axismodel and research methods. Soil Biology and Biochemistry, 43 (5), 883-894.

[52] Mekonnen, F. (2007) 'Adaptation and agronomic performance of chickpea varieties in northeastern Amhara', 85-92.

[53] MeseretTuruko, and Amin Mohammed., (2014). Effect of different phosphorus fertilizer rates on growth, dry matter yield and yield components of common bean (Phaseolus vulgaris L.). World Journal of Agricultural Research, 2 (3), 88-92.

[54] Miguel, M. A., Postma, J. A. and Lynch, J. P., (2015). Phene synergism between root hair length and basal root growth angle for phosphorus acquisition. Plant Physiology, 167 (4), $1430-1439$.

[55] Miguel, M. A., Postma, J. A. and Lynch, J., (2013). Phene synergism between root hair length and basal root growth angle for phosphorus acquisition. Plant Physiology. 167, $1430-1439$. 
[56] Miller, c., Ochoa, I., Nielson, K., Beck, D., Lynch, J., (2003). Genetic variation for adventitious rooting in response to low phosphorus availability: potential utility for phosphorus acquisition from stratified soils. Functional plant Biology. 30, 973-985.

[57] Mulugeta A (2011) Factors affecting the adoption of improved haricot bean varieties and associated agronomic practices in Dale woreda. SNNPRS, M.Sc. Thesis in Plant Sciences (Agronomy), Hawassa University, Ethiopia, Africa.

[58] Munuve, H. K., (2016). Effects of phosphorus and soil moisture on grain yield, leaf and grain tissue concentration of iron and zinc in three bean (phaseolusvulgarisl. L) genotypes (Doctoral dissertation).

[59] Mwanauta, R. W., Mtei, K. M. and Ndakidemi, P. A., (2015). Potential of Controlling Common Bean Insect Pests (Bean Stem Maggot (Ophiomyia phaseoli), Ootheca (Ootheca bennigseni) and Aphids (Aphis fabae)) Using Agronomic, Biological and Botanical Practices in Field. Agricultural Sciences, 6 (05), 489.

[60] Mweetwa, A. M., Chilombo, G. and Gondwe, B. M., (2016). Nodulation, nutrient uptake and yield of common bean inoculated with Rhizobia and Trichoderma in an Acid Soil. Journal of Agricultural Science, 8 (12), 61.

[61] Namugwanya Margaret, John Stephen Tenywa1, Erasmus Otabbong, D. N. M. and T. A. B. (2014) 'Development of Common Bean ( Phaseolus vulgaris L.) Production Under Low Soil Phosphorus and Drought in Sub-Saharan Africa: A Review', 7 (5), 128-139.

[62] Negash, R, (2007). Determinants of adoption of improved haricot beans production package in Alaba Special Woreda, Southern Ethiopia, M.Sc. thesis, Haramaya University, Ethiopia

[63] Niu, Y. F., Chai, R. S., Jin, G. L., Wang, H., Tang, C. X. and Zhang, Y. S., (2012). Responses of root architecture development to low phosphorus availability: AReview. Annals of Botany, 112 (2), 391-408.

[64] Okii, D., Tukamuhabwa, P., Odong, T., Namayanja, A., Mukabaranga, J., Paparu, P. and Gepts, P., (2014). Morphological diversity of tropical common bean germplasm. African Crop Science Journal, 22 (1), 59-68.

[65] Rao, I. M., Miles, J. W., Beebe, S. E. and Horst, W. J., (2016). Root adaptations to soils with low fertility and aluminum toxicity. Annals of Botany, 118 (4), 593-605.

[66] Salinas, J. G. (1978). Differential response of some cereal and bean cultivars to $\mathrm{Al}$ and $\mathrm{P}$ stress in an oxisol of central Brasil. PhD Diss., Raleigh, North Carolina State Univ., Raleigh.

[67] Sanchez-Calderón, L., Ibarra-Cortés, M. E. and Zepeda-Jazo, I., (2013). Root development and abiotic stress adaptation. In Abiotic Stress-Plant Responses and Applications in Agriculture. 23 (5-7), 101-113.

[68] Sanchez, P. A. and Salinas, J. G., (1981). Low-input technology for managing Oxisols and Ultisols in tropical America. In Advances in agronomy 34, 279-406.

[69] Shenoy, V. V. and Kalagudi, G. M., (2005). Enhancing plant phosphorus use efficiency for sustainable cropping. Biotechnology Advances, 23 (7-8), 501-513.
[70] Shumi D, Alemayehu D, Afeta T, and Debelo B. (2018). Response of Common bean (Phaseolus vulgaris L.) Varieties to Rates of Blended NPS Fertilizer in Adola District, Southern Ethiopia. Journal of Plant Biological Soil Health. 5 (1): 1-12

[71] Simane, B., (1998) 'No Title: Haricot bean Agroecology in Ethiopia', 6 (1), 9-18.

[72] Slattery J., M. Ridley and M. Windsor, (1999). Ash alkalinity of animal and plant products. Australian Journal of Experimental Agriculture 31: 321-324.

[73] Tesfaye, A., Githiri, M., Derera, J. and Debele, T., (2017). Genetic variability in soybean (Glycine $\max L$.) for low soil phosphorus tolerance. Ethiopian Journal of Agricultural Sciences, 27 (2), 1-15.

[74] Tapia, B. H. (1987). Variedadesmejoradas de frijol Phaseolus vulgaris L. con granorojo para Nicaragua. Instituto Superior de CienciasAgropecuarias. Dirección de Investigación y Postgrado, Managua, Nicaragua.

[75] Thung, M. (1990). Phosphorus: A limiting nutrient in bean (Phaseolus vulgaris L.) production in Latin America and field screening for efficiency and response, In: N. El Bassam, M. Dambroth, and B. C. Loughman (eds). Genetic aspects of plant mineral nutrition. Kluwer Academic Publishers, The Netherlands, 501-521.

[76] White, W. B., Cannon, C. P., Heller, S. R., Nissen, S. E., Bergenstal, R. M., Bakris, G. L., Perez, A. T., Fleck, P. R., Mehta, C. R., Kupfer, S. and Wilson, C., (2013). Alogliptin after acute coronary syndrome in patients with type 2 diabetes. New England Journal of Medicine, 369 (14), 1327-1335.

[77] Wolff, A. B., Sidirelli, M., Paradellis, C. and Kotzabasis, K., (1995). Influence of acid soil on nodule numbers in relation to polyamine and tannin concentrations in roots of Phaseolus vulgaris. Biology and fertility of soils, 20 (4), 249-252.

[78] Wolff, A. B., Singleton, P. W., Sidirelli, M. and Bohlool, B. B., (1993). Influence of acid soil on nodulation and interstrain competitiveness in relation to tannin concentrations in seeds and roots of Phaseolus vulgaris. Soil Biology and Biochemistry, 25 (6), 715-721.

[79] Yan, X., Lynch, J. P. and Beebe, S. E., (1995). Genetic variation for phosphorus efficiency of common bean in contrasting soil types: I. Vegetative response. Crop Science, 35 (4), 1086-1093.

[80] York LM, Nord EA, Lynch JP. (2013). Integration of root phenes for soil resource acquisition. Frontiers in Plant Science 4 (Article 435): 1-15.

[81] Zahran, H. H. (1999) 'Rhizobium-legume symbiosis and nitrogen fixation under severe conditions and in an arid climate.', Microbiology and molecular biology reviews: $M M B R, 63$ (4), 968-89.

[82] Zhang XB, Peng L, Yang YS, Gen-Di Xu (2007). Effect of Al in soil on photosynthesis and related morphological and physiological characteristics of two soybean genotypes, Botanical Studies, 48: 435-444. 